$9-1-1990$

\title{
The changing role of prevention in dental education.
}

Brian M. Lange

University of Nebraska Medical Center, blange@unmc.edu

David G. Dunning

University of Nebraska Medical Center, ddunning@unmc.edu

Graham Shea

V.A. Medical Center-Portland

Tell us how you used this information in this short survey.

Follow this and additional works at: https://digitalcommons.unmc.edu/cod_articles

Part of the Dentistry Commons

\section{Recommended Citation}

Lange, Brian M.; Dunning, David G.; and Shea, Graham, "The changing role of prevention in dental education." (1990). Journal Articles: College of Dentistry. 16.

https://digitalcommons.unmc.edu/cod_articles/16

This Article is brought to you for free and open access by the College of Dentistry at DigitalCommons@UNMC. It has been accepted for inclusion in Journal Articles: College of Dentistry by an authorized administrator of DigitalCommons@UNMC.For more information, please contact digitalcommons@unmc.edu. 


\section{The Changing Role Of Prevention In Dental Education}

\author{
Brian M. Lange, Ph.D.; David G. Dunning, Ph.D.; Graham Shea, D.D.S.
}

In 1962, Blackerly determined, through an examination of the catalogs of 44 dental schools, that a mean of six clock hours was devoted to teaching students about preventive dentistry, ${ }^{1}$ By 1968 , the American Dental Association's Council on Dental Education reported that the mean clock hours of curriculum time devoted to preventive dentistry in 44 responding schools had risen to 28.4 . $^{2}$ In a 1979 survey ${ }^{3} 41$ of the 51 respondents answered the questions relating to didactic course hours in preventive dentistry, indicating a mean of 38 hours, with a range of two to 100 hours. Among 34 schools answering the question total clinical hours ranged from one to 184 with a mean of 39. The survey also showed that 28 (56 percent) of the responding schools had specific departments in which preventive dentistry was taught. Furthermore, 47 of the 51 responding schools indicated that students counseled patients on preventive care. At the time of Ayers, Williams, and Lausten study, preventive instruction represented 1.8 percent of the total dental school curriculum and the dental students typically received the majority of their preventive instruction in the first two years.

Theintent of this report is to summarize the results of a survey of U.S. and Canadian dental schools regarding the current role of preventive dentistry in undergraduate curriculum.

\section{Methods}

In 1988, a questionnaire was constructed to obtain data from dental schools on didactic and clinical cur- riculum time allotted to departments or areas responsible for teaching preventive dentistry. In addition, the survey also included questions regarding when and how in the curriculum dental students were held accountable for teaching preventive concepts to their patients.

The questionnaire was mailed to all dental schools in the United States, Canada, and the dental college in Puerto Rico. A reminder letter was sent to schools that took longer than four weeks to respond. Out of the 68 schools surveyed, 56 responded for a return rate of 82 percent. Forty-six of the U.S. dental colleges responded-return rate of 81 percent. All of the Canadian dental colleges and the dental college in Puerto Rico responded. Due to uniqueness of dental curricula and the fact that not all respondents answered every question, frequency counts varied slightly from question to question.

\section{Results}

Twenty-two of the U.S. schools (including Puerto Rico) and eight of the Canadian schools identified specific departments that had primary responsibility for teaching preventive dentistry. Four of the U.S. schools indicated that this responsibility was held by multiple sections/departments, including oral biology, general dentistry, and oral diagnosis. Virtually all the dental schools not having a department with primary responsibility for teaching prevention indicated they had either a department or multiple departments (18 schools) that had teaching prevention as one of its charges.

Twenty-three of the U.S. and four of the

Drs. Lange and Dunning are at the Department of Dental Practice Management, University of Nebraska Medical Center, College of Dentistry, 40th and Holdrege Streets, Lincoln, NE 68583. Dr. Shea is at GPR Residency, VA Medical Center, Portland, OR 97266. Send correspondence to Dr. Lange.

Canadian schools indicated that they hold dental students responsible and accountable for their personal oral hygiene via course requirements and/or clinical checks. Two U.S. and one Canadian school indicated that they held students responsible but not accountable for their personal oral hygiene. The remaining 21 of the U.S. schools and five of the Canadian schools indicated that they did not hold students either responsible or accountable for their own oral hygiene.

The majority of U.S. (30) and Canadian (6) dental schools didactically introduce dental students to preventive concepts through didactic instruction in the first semester of the first year of dental school. Another 11 of the U.S. schools and none of the Canadian dental schools introduced preventive concepts in the first year, second semester. Two of the remaining U.S. schools and all four remaining Canadian schools introduced preventive concepts in the first semester of thesecond year. Two U.S. schools introduced preventive concepts in the second semester of the second year.

The majority of didactic training occurs in the first year. Twenty-seven of the U.S. dental schools and four of the Canadian dental schools indicated that 51 percent to 100 percent of the didactic preventive curriculum was taught in the first year, another 10 of the U.S. schools and four of the Canadian schools indicated that 51 to 100 percent of the preventive curriculum was taught in the second year. Three U.S. and one of the Canadian schools utilize the third year for emphasizing preventive concepts. The remaining five of the U.S. and one of the Canadian schools indicated that preventive concepts received equal didactic emphasis throughout the four years of dental school.

Table 1 reports the didactic and clinical clock hours devoted to preventive den- 
tistry. A total of 44 U.S. and 10 Canadian schools responded to the question relating to didactic clock hours. Thirty-seven of the U.S. and seven of the Canadian schools responded to the question relating to the number of clinical clock hours devoted to prevention. The didactic clock hours for the U.S. and Canadian schools ranged from two to 105 with the mean for U.S. schools being 32 hours and the mean for Canadian schools being 45 hours. The clinical clock hours in preventive dentistry for both the U.S. and Canadian schools ranged from two to 105 hours with the mean of 57 for the U.S. schools and a mean of 54 hours for the Canadian schools. Two U.S. and one of the Canadian schools not included in the data of Table 1 indicated that all patients receive either instruction in prevention or preventive checks if they had previously received instruction.

A total of 44 U.S. and 10 Canadian schools responded to a two-part question asking if students were expected to provide specific types of preventive instruction to patients they treated. A total of 32 U.S. schools and six Canadian schools indicated they held students accountable for practicing preventive dentistry. Table 2 summarizes the methods the reporting schools indicated they expected students to use in teaching prevention to their patients.

\section{Discussion}

Since Canadian and U.S. dental schools share similar goals and experiences, it is not surprising that the preventive programs in the two regions are comparable in terms of time allocation, requirements, and evaluation procedures. However, one difference deserves mention. Overall, Canadian schools devote approximately nine more hours to teaching prevention-four fewer clinical hours but 13 more didactic hours. The last survey in the U.S. to examine the numbers of didactic and clinical hours spent in teaching dental students preventive skills was 11 years ago and included only dental schools in the United States. Since the last survey, dental schools in the U.S. have decreased in number, lost federal support for preventive programs, have undergone a great deal of self-examination in light of shrinking budgets and applicant pools. In spite of all the environmental changes, dental education has maintained a commitment to teaching preven-

Table 1. Curriculum Clock Hours in Preventive Dentistry.

\begin{tabular}{lcccc}
\hline Total hours & \multicolumn{2}{c}{$\begin{array}{c}\text { Didactic Clock } \\
\text { Hours of Instruction }\end{array}$} & \multicolumn{2}{c}{$\begin{array}{c}\text { Clinical Clock } \\
\text { Hours of Instruction }\end{array}$} \\
\hline & U.S. & $\begin{array}{c}\text { Canadian } \\
(\mathrm{N}=10)\end{array}$ & $\begin{array}{c}\text { U.S. } \\
(\mathrm{N}=37)\end{array}$ & $\begin{array}{c}\text { Canadian } \\
(\mathrm{N}=7)\end{array}$ \\
\hline $1-10$ & 4 & 0 & 2 & 1 \\
$11-20$ & 7 & 2 & 4 & 0 \\
$21-30$ & 10 & 1 & 6 & 2 \\
$31-40$ & 13 & 1 & 1 & 0 \\
$41-50$ & 5 & 4 & 3 & 1 \\
$51-60$ & 2 & 0 & 5 & 1 \\
$61-70$ & 1 & 0 & 3 & 1 \\
$71-80$ & 1 & 1 & 3 & 0 \\
$81-90$ & 0 & 0 & 1 & 0 \\
$91-100$ & 0 & 0 & 1 & 1 \\
$101+$ & 1 & 1 & 8 & \\
\hline
\end{tabular}

Table 2. Summary of Methods Expected to be used by Students to Teach Preventive Concepts.

\begin{tabular}{lcc} 
Methods & U.S. (\%) & Canadian (\%) \\
\hline Plaque indices & 94 & 93 \\
Periodontal probing & 88 & 93 \\
Counseling (brushing and flossing, & 97 & 100 \\
$\quad$ general oral hygiene concepts) & & \\
Dietary analysis & 81 & 67 \\
Audiovisual material & 40 & 33 \\
Other & 28 & 17 \\
\hline
\end{tabular}

tive concepts to future generations of dentists. The focus of teaching prevention has changed. The mean number of didactic clock hours has decreased from 38 to 32 while the mean number of clinical clock hours has increased from 39 to 57 . As a result the total number of preventive hours for a four year program has increased by 12 . For U.S. schools, prevention based curriculum hours have increased from 77 in 1979 to 89 in 1989. The data from the questionnaires indicate that most schools are integrating preventive maintenance strategies into the clinical management of patients. Students are required to go over preventive measures with patients and to check on the oral hygiene of patients upon recall.

The focus of the preventive curriculum has shifted from emphasizing didactic content to clinical application, and it appears to be patient centered. The emphasis on average didactic and clinical curriculum hours may be replaced by devoting a portion of each patient appointment to teaching or reinforcing excellence in maintaining oral health.

The dental literature of the $1960 \mathrm{~s}$ did much to focus dental education and the federal government on the need to teach dental professionals preventive oral health concepts. By the early 1970 s dental schools receiving capitation funds were influenced to develop community and preventivedentistry departments. Theintent or focus of these new departments was to teach a new generation of dental health care professionals how to incorporate oral preventive philosophies into their dental practice. It appears that the grass roots preventive movement of dental practitioners combined with the efforts of dental educators and the influence of federal government requirements for continued funding led to the rapid expansion of preventive dental programs seen in the early $1970 \mathrm{~s}$.

The maturation of preventive programs over the last three decades can becompared to human development. The 1960 s can be described as prevention in its infancy, as evidenced by the number of articles in the dental literature pointing to the benefits of oral prevention and calling for dental school involvement in teaching preventive concepts. ${ }^{46}$ The 1970 s can be 
compared to childhood, a period of rapid growth. Many preventive programs were described in the dental literature of the 1970 s. $^{7-10}$ The preventive dental literature of the 1970s also began to address questions such as what, when and how preventive concepts should be taught to dental students. ${ }^{1 \mathrm{r}}$ The dental literature of the 1980 s represented adolescence. Articles were published on the difference between education and prevention, ${ }^{12}$ suggesting and describing prevention as a part of treatment, and planning for the preventive needs of future generations. ${ }^{13,14}$ As preventive dentistry continues to mature, future directions may include the preventive education needs generated by growing numbers of dental implants, and the preventive needs of an increasing "greying" population, and testing methods of teaching prevention to this "greying" population.

\section{References}

1. Blackerly PE. Department of social dentistry: a review in social dentistry. Seminar proceedings, Washington, DC Government Printing Office, 1965.

2. American Dental Association Council on Dental Education, Chicago: American Dental Association, 1968.

3. Ayers C, Williams D, Lausten L. A survey of prevention in dental education. J Dent Educ 1979;43:515-6.

4. Blackerly PE. Social dentistry: the curricular orphan. J Amer Coll Dent 1965;32:277-83.

5. Glass R. Motivation for preventive dentistry. J Dent Educ 1968;32:290-5.

6. Sumnicht $R$. The gap between expectations and reality in preventive dentistry. J Dent Educ 1968;32:48-53.

7. Brown W. Prevention-its role in the curriculum of a new dental school. J Amer Coll Dent 1973;40:29-53.
8. Gold S. The challenge of prevention in a dental school. J Prevent Dent 1974;1(3):358.

9. Moore D. Preventive dentistry in action in a dental college. J Dent Educ 1976;40(6):349-54.

10. Phair P. Challenges in the prevention of dental diseases and the response of the college of dentistry. Iowa Dent J 1977;64:31-4.

11. Silberman S, Yacovone J. Preventive dentistry a conceptual model for a dental school. Clin Prevent Dent 1979;6(1):29-34.

12. Burt $B$. The preventive connection: linking dental health education and prevention. Int Dent J 1983;33(2):188-195.

13. Morris A. Dentistry in 1990: premises and promises. NY State Dent J 1984;50(2):8790,92,94-97.

14. Allen $D$. The implications of changing patterns in oral health for dental education. Int Dent J 1985;35:83-87. 